\title{
Role Playing Games and Emotions in Dispute Resolution Environments
}

\author{
Davide Carneiro, Paulo Novais, Luís Machado, Cesar Analide, Nuno Costa, \\ José Neves \\ Department of Informatics \\ University of Minho, Braga, Portugal \\ \{dcarneiro, pjon, analide, jneves\}@di.uminho.pt, luisp_machado@hotmail.com, \\ nuno.costa.78@gmail.com
}

\begin{abstract}
Electronic contracting, mostly through software agents, led to an impressive growth in electronic transactions, but also in the number of disputes arising out of these transactions. Paper-based courts are however unable to efficiently deal with this increase in disputes. On the other hand, current Online Dispute Resolution methodologies are impersonal and cold, leaving aside important information such as the disputants' body language and emotions. In that sense, in this paper we propose the creation of environments for dispute resolution that can complement the existing tools with important context information. This, we believe, will lead to dispute resolution tools that will more efficiently achieve mutually satisfactory outcomes.
\end{abstract}

Keywords: Affective Computing, Role Playing Games, Emotions, Ambient Intelligence, Dispute Resolution Environments.

\section{Introduction}

The increase in the transaction volume of global B2C e-Commerce led to a whole new way of doing commerce globally. Now, we talk of electronic contracting performed in part or wholly by means of electronic agents. However, disputes are still likely to arise in these transactions, namely because of late shipments or products of low quality. Evidently courts, shaped after the industrial era and still paper-based, are not ready for both the amount and the new characteristics of these disputes. The immediate consequence is an increase in the waiting queues of courts, rendering judicial systems slow and unresponsive.

On a first attempt to address this problem, in the last century several alternatives to litigation in courts started to be adopted - the so called Alternative Dispute Resolution methods, including negotiation, mediation and arbitration [1]. With the advent of the Information Society, these techniques are starting to be 
implemented in virtual environments also, leading to what is known as Online Dispute Resolution [2]. On its most basic form, Online Dispute Resolution simply implements already traditional methods over a communication mean, i.e., instead of negotiating in person, the disputant parties do it over a phone line or any other communication mean. However, the latest research trends show that the role of technology in dispute resolution can be further enhanced, namely by using techniques from Artificial Intelligence [3]. In such ODR systems, technology will be used not only to put parties into contact but also to suggest solutions, plan strategies or compile useful information.

However, this approach still has some flaws. Namely, when parties use an online tool, a significant amount of important information is lost. This information includes body language, context information or even the emotional state. All this would be taken into account by a judge or a jury in a litigation in court, but is lost when using an ODR tool. Its main usefulness is in determining how each aspect of the dispute resolution process affects the party (e.g. is the party happy with the proposed solution?, does the party fill threatened when talking to the other party?, is the party nervous when addressing a specific issue?). The development of ODR systems that are indeed able to understand the emotional state of the parties is thus of the utmost importance.

The use of soft computing techniques can be the answer to this challenge [17, 18]. Therefore, in this paper, we present a novel approach, based on three key paradigms: Ambient Intelligence (AmI), Role-Playing Games (RPG) and Emotions. Ambient Intelligence is a recent technological paradigm in which traditional environments are empowered with the objective of providing useful context-aware services. Role-Playing Games are a type of game in which players "interpret" a character created in a given scenario (environment), allowing to create "social laboratories" [4, 5]. Finally, emotions are represented as proposed by William James [6] and Carl Lange [7]. This theory essentially suggests that emotions are the result of a response of human physiological external stimuli, i.e., every emotion is associated with a different physiological response [8].

Thus this allows us to assume that by analyzing physiological responses, one can determine the emotional state of a subject. The approach presented in this paper develops around this idea. Therefore, we present the notion of an intelligent environment for dispute resolution, in which the determination of the emotional state of the parties is an important step for efficiently achieving a mutually satisfactory outcome. Our vision is that parties can be in their own environments, using an ODR tool to solve a conflict, with the respective environments collecting important information and sharing it with the dispute resolution tool. To materialize it, we are bringing together two projects: VirtualECare and UMCourt. 


\section{Ambient Intelligence and Online Dispute Resolution}

UMCourt and VirtualECare are two research projects maintained by the Intelligent System Research Team, at the University of Minho. The VirtualECare project [9, 10] focuses on the Ambient Intelligence paradigm and has as main objective to develop an agent-based environment able to monitor, interact and provide its customers with services of the utmost quality. In that sense, the system is able to read environmental and contextual information from its user's environment, including environmental conditions, emotional state, physiological state, among others. This system will be interconnected not only to institutions and other architectures and systems, but also to leisure centers, training facilities, shops and patient relatives, just to name a few. VirtualECare's architecture (Figure 1) is a distributed one, bringing together two technologies: OSGi and Jade. OSGi services are used to connect agents and devices, hiding their singularities and allowing their functionalities to be accessed as standard services. Jade agents, on the other hand, are in charge of all the analysis and decisions making processes. VirtualECare also implements an OSGi-based fully functional simulation platform that allows for the creation and study of specific scenarios. All the data generated, either by an actual implementation of the system or by the simulation platform, is available to external entities by means of OSGi services.

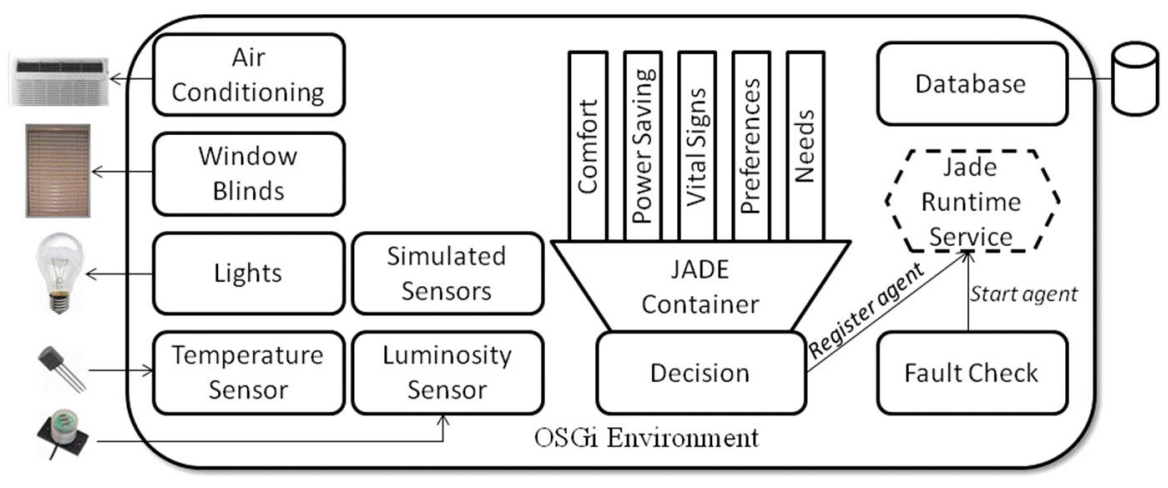

Fig. 1. A simplified view of the VirtualECare architecture.

UMCourt, on the other hand, is a project that aims at the development of a multi-faceted agent-based ODR architecture, suited to be used in different legal domains [11]. The main objective is to empower the role of the parties in the dispute resolution process by providing meaningful and contextualized information, proposing solutions, strategies and guidance by means of mediation and negotiation algorithms. Similarly to VirtualECare, this architecture (Figure 2) is also based on OSGi and Jade. This was the main reason that allowed these two projects to come together, laying the path to a new research direction: Dispute 
Resolution Environments. A detailed description of the architecture and the implemented services is given in $[12,13]$.

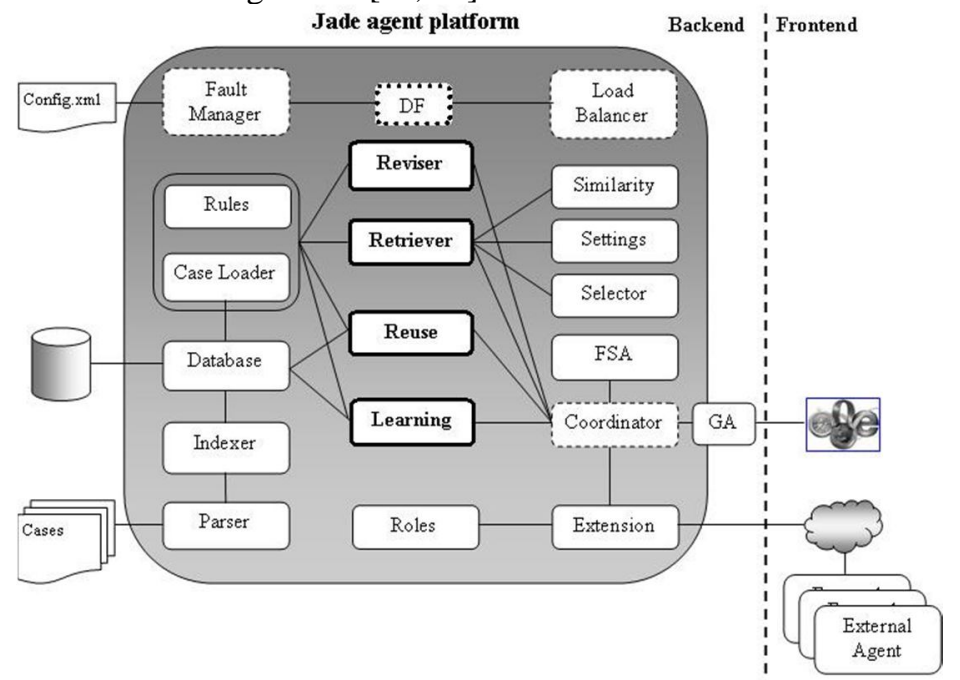

Fig. 2. The organization of the agents that make up the UMCourt architecture.

\section{Intelligent Environments for Dispute Resolution}

Simulation is paramount when it comes to create critical real-world scenarios where the margin of error must be minimal. Thus, at this point, we are making use of the VirtualECare simulation tool in order to gather information about the parties, their context and their emotional state. This information is then considered by UMCourt when performing its tasks.

The simulation tool allows simulating one instance of an intelligent environment setting, fully configurable in terms of the devices, rooms, physical properties, user actions, internal and external atmospheric conditions, among others. This means that the tool allows simulating specific sensors such as temperature or humidity sensors but also vital sign ones. However, given the focus of this work, we will rather focus on the simulation of the emotional state of the parties as an input for UMCourt. In that sense, UMCourt is able to determine how a party fells about a given decision or issue, allowing to adapt and fine-tune strategies. We are also interested in the possibility of creating user groups, based on role-playing games, in which each player can embody a certain character, with a given role and permissions (e.g. mediator, plaintiff, defendant, neutral). The objective, in the long term, is to replace the simulated sensors by real ones, in order to implement an actual dispute resolution environment able to compile all this important information. 


\subsection{Simulation of Users}

One useful feature in the simulation tools concerns the possibility to simulate different user-types. These types are created based on role playing games techniques, i.e. each user-type will represent a different pre-defined role on the environment, which enables him to perform different actions. Thus, the system allows to define the different actions that each role can perform inside the house (Figure 3). The use of role-playing game techniques permits the distinction of the different user groups with specific characteristics. It also allows to assign different conflict styles to each user group, denoting the way that each one has to deal with the conflict.

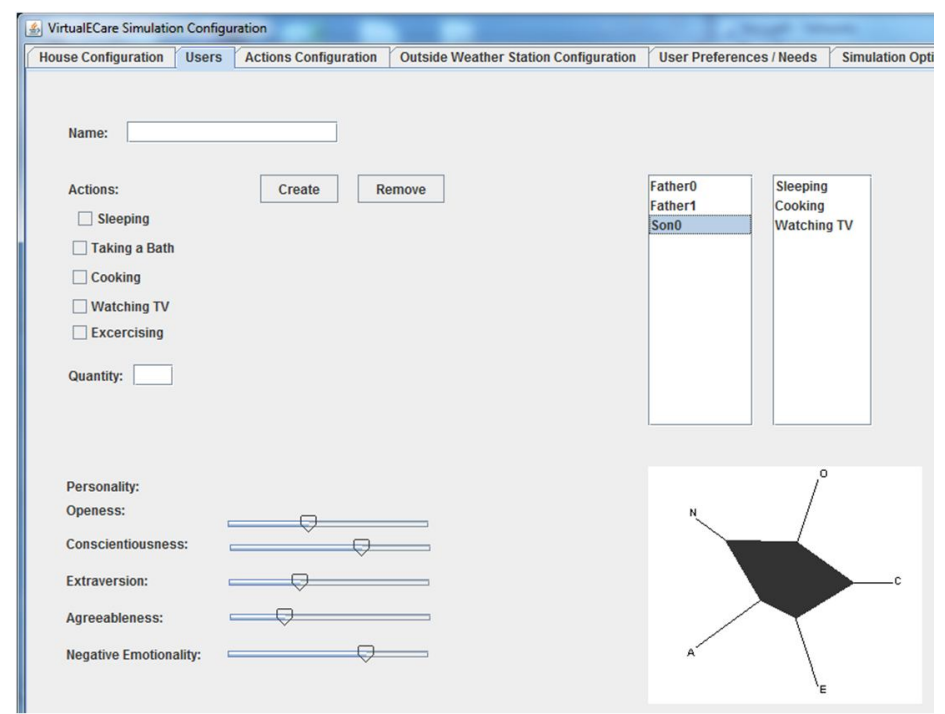

Fig. 3. A detail of the configuration of the users, including roles and personality types.

This tool also allows simulating vital signs. As these are one of the most important factors in determining the emotional state of an individual, UMCourt also makes use of that information (Figure 4). By creating different vital sign configurations, one can induce specific scenarios and see how the inference mechanisms create the associated emotional state of a party and, consequently, how UMCourt adapts its models according to it. The simulation tool allows to independently configure the vital signs of each user. When doing this, two modes are possible: the Random mode and the Planned mode. In Random mode, the vital signs of the different users can be configured to develop randomly, according to configurable Gaussian functions. Alternatively, in the Planned mode, these vital signs can be completely planned. This means that it is possible to configure the exact vital signs of a user in each time instant of the simulation. This allows us to, 
for example, induce a given physiological state for a given time instant and assess how the system reacts to it.

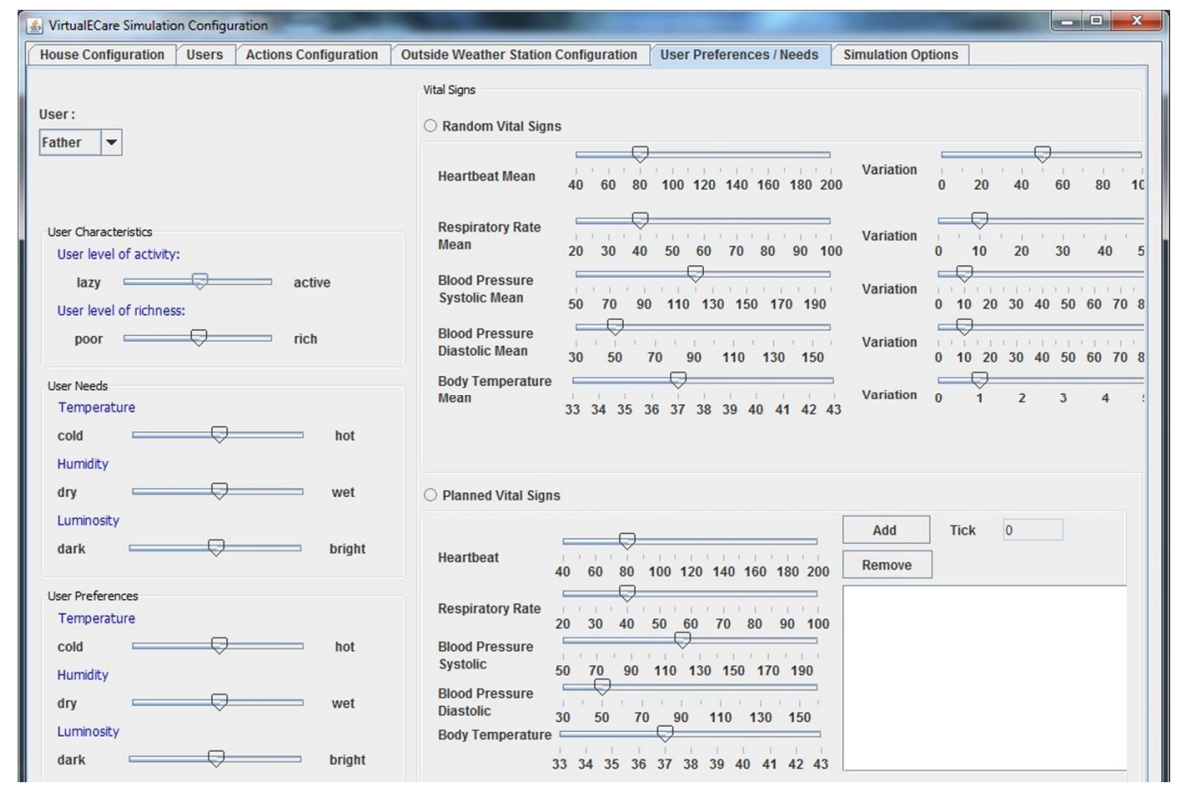

Fig. 4. A detail of the configuration the vital signs of a given user.

\subsection{Simulation of Emotions}

As said before, the simulation tool can also provide information regarding the simulated users that allows us to determine their emotional state at every moment. In order to simulate the emotions of a user in a realistic fashion, we are making combined use of the user objectives, the state of the environment and the type of personality. For example, if the user has as objective to maximize his personal gain at all cost and the most likely outcome of the dispute resolution process is one in which his gains are low, the simulated emotion will be between sadness and disappointment. The time that this emotion lasts as well as its intensity is determined by the personality type. To model the personality of each user the [14] model is being used, also known as OCEAN (Openness, Conscientiousness, Extroversion, Agreeableness and Negative emotionality) which is the model of personality that brings greater consensus at the global level [14].

To define the emotions, we are using a simplification of the OCC theory [15]. Thus, at this moment, our emotional model considers the following basic emotions: happiness, sadness, fear, anger, disappointment and surprise. When defining this basic set of emotions, we also had in mind what would be the most suited emotions to express the opinion of the user about a suggestion or action of 
the system. Evidently, the same actions will trigger different emotions on different users, depending on the personality type. Moreover, the system is able to infer the emotional state of the dispute resolution environment as the intersection of the emotional state of each of the participants in the dispute resolution process. This is useful when the system must perform an action in the common scenarios in which there is a conflict of interests. In this sense, two approaches can be followed. On the one hand, the system can be configured to satisfy the emotions of a particular user or of a user with a given role. On the other hand, the system can be configured to maximize the satisfaction of all the users in the environment, in which case the mean of the preferences and the information about the emotional state of the environment are considered.

\section{Conclusion and Future Work}

Current trends of development of ODR tools are not considering important information such as body language or emotional states. This happens because current tools rely basically on web interfaces. In order to address this problem, we proposed a new approach, based on intelligent environments. In that sense, we argue that current tools must be complemented by environments that are able to acquire important context information about the parties and their surroundings. Using this information, ODR tools would be able to determine to which extent a suggestion, an action or a given topic affects each party and, this way, adapt strategies in order to more efficiently achieve more mutually satisfactory outcomes. Given the complexity of such environments, we are currently using information generated by the simulation tool as input for UMCourt. This allows us to create specific scenarios, with specific user-types and determine how UMCourt adapts its strategies accordingly (case retrieval, solution proposal, mediation and negotiation conduction). In future work, we intend to take small steps towards the actual implementation of a real test environment. This includes the acquisition of sensors that will gradually replace the sensors currently being simulated. We are also currently building a database of cases that store the emotional state before and after given actions taken by the ODR system. This allows us to use a nearest neighbor retrieval algorithm to examine past cases and predict, at each time and based on the conflict styles, how a given action may affect each party. This will allow the system, for example, to determine at which point a party moves from an avoiding conflict style to a compromising one [16]. In fact, the determination of the conflict styles is a very important feature for a mediator. In future work we also intend to use machine learning techniques such as classification in order to make the selection of cases and compare their effectiveness with the one of the retrieval algorithm. This, we believe, is the path to develop ODR tools that encompass very important context information that is being ignored by current research trends. 
Acknowledgments. The work described in this paper is included in TIARAC Telematics and Artificial Intelligence in Alternative Conflict Resolution Project (PTDC/JUR/71354/2006), which is a research project supported by FCT (Science \& Technology Foundation), Portugal.

\section{References}

1. Brown, H., Marriott, A.: ADR Principles and Practice. Sweet and Maxwell. (1999)

2. Katsch E., Rifkin J.: Online dispute resolution - resolving conflicts in cyberspace. Jossey-Bass Wiley Company, San Francisco. (2001)

3. Lodder, A., Thiessen, E.: The role of artificial intelligence in online dispute resolution. In Workshop on Online Dispute Resolution at the International Conference on Artificial Intelligence and Law, Edinburgh, UK. (2003)

4. Y, Nick. The Psychology of Massively Multi-User Online Role-Playing Games: Motivations, Emotional Investment, Relationships and Problematic Usage. In Avatars at Work and Play, Computer Supported Cooperative Work, vol. 34, pp. 187-207. (2003)

5. Barreteau, O., Le Page, C. and D'Aquino, P.: Role-Playing Games, Models and Negotiation Processes. In Journal of Artificial Societies and Social Simulation, vol. 6, no. 2. (2003)

6. James, W. What is an Emotion?. In: Mind, vol. 9, no. 34, pp. 188-205. (1884)

7. Lange, C. The emotions. New york: Harner Publishing co. (1967)

8. Cannon, W. The James-Lange Theory of Emotions: A Critical Examination and an Alternative. In The American Journal of Psychology, vol. 39, pp. 106-124. (1927)

9. Costa, R., Novais, P., Lima, L., Carneiro, D., Samico, D., Oliveira, J., Machado, J., Neves. J. VirtualECare: Intelligent Assisted Living. In Electronic Healthcare, Dasun Weerasinghe (ed.), Springer-Verlag, pp. 138-144. (2009)

10. Costa, R., Carneiro, D., Novais, P., Lima, L., Machado, J., Marques, A., Neves, J. Ambient Assisted Living. In: Advances in Soft Computing, vol. 51, Springer- Verlag, pp. 86-94. (2008)

11. Andrade, F., Novais, P., Carneiro, D., Neves, J.: Conflict Resolution in Virtual Locations. In Information Communication Technology Law, Protection and Access Rights: Global Approaches and Issues. Portela, I., Cunha, M. (Eds), IGI Global. (2010)

12. Carneiro, D., Novais, P., Costa, R., Neves, J. Developing Intelligent Environments with OSGi and JADE, The Third IFIP International Conference on Artificial Intelligence in Theory and Practice. (2010)

13. Carneiro, D., Novais, P., Andrade, F., Zeleznikow, J., Neves, J.: The Legal Precedent in Online Dispute Resolution. In Legal Knowledge and Information Systems, ed. Guido Governatori, Proceedings of the Jurix 2009, pp. 47-52 (2009)

14. Mccrae, R., Costa, P., Martin, T.: The neo-pi-3: A more readable revised neo personality inventory. In: Journal of Personality Assessment, 84 (3):261-270 (2005)

15. Ortony, A., Clore, G., Collins, A.: The cognitive structure of emotions. University Press. (1988)

16. Carneiro, D., Novais, P., Andrade, F., Neves, J.: Using Mediation to Solve Disputes with Avoiding Parties. In Proceedings of the Fourth International Workshop on JurisInformatics (Jurisin 2010), pp. 17-28. (2010)

17. Sedano J., Curiel, L., Corchado, E., Cal E., Villar, J.: A soft computing method for detecting lifetime building thermal insulation failures. In Integrated Computer-Aided Engineering, Vol. 17, Issue 2 , pp. 103-115, IOS Press. (2010)

18. Corchado, E., Arroyo, A., Tricio V.: Soft computing models to identify typical meteorological days. In: Logic Journal of the IGPL, Oxford University Press. (2010) 